\section{lodação do sal no Brasil, um assunto controverso}

\author{
Salt iodation in Brazil, a controversial subject
}

\begin{abstract}
Alana Abrantes Nogueira de Pontes' ${ }^{1}$, Aline da Mota Rocha', Débora Farias Batista Leite', Andréa da Fonseca Lessa², Luís Fernando Fernandes Adan ${ }^{3}$
\end{abstract}

A Organização Mundial da Saúde (OMS) considera a deficiência de iodo um grave problema de saúde pública no mundo, principalmente, em grávidas e em crianças (1). O cientista francês Boussingault foi o primeiro a sugerir a adição de iodo ao sal comum como método de prevenção do bócio, em 1831 (2). Essa intervenção nutricional com a adição de iodato de potássio ao sal teve e tem eficácia universalmente comprovada (1). No Brasil, só em 1953 foi promulgada a primeira Lei $\left(\mathrm{n}^{\circ} 1.944,14\right.$ de agosto de 1953$)$ obrigando a iodação do sal para consumo humano (3). Em 2003, a Agência Nacional de Vigilância Sanitária (Anvisa), por meio de Regulamentação de Diretoria Colegiada (RDC, $\left.\mathrm{n}^{\circ} 130\right)$, normalizou entre 20 e $60 \mathrm{mg} / \mathrm{kg}$ a concentração ideal de iodo no sal para consumo humano (3).

Os dados coletados em 1994 por Esteves $(4,5)$, e publicados em 2007, refletem a situação daquele momento. Os autores usaram critérios estatísticos ao considerar que, além dos 85 municípios, onde as medianas foram inferiores a $10 \mu \mathrm{g} / \mathrm{dL}, 35$ outros municípios apresentaram mais de $10 \%$ das amostras com níveis inferiores a 2,5 $\mu \mathrm{g} / \mathrm{dL}$ (deficiência grave), o que foge da distribuição normal das iodúrias em uma população. Neste estudo, portanto, foram considerados deficientes 120 municípios, sendo detectados níveis compatíveis com deficiência leve em dois municípios do estado da Paraíba (PB): Arara e Juazeirinho (mediana $9,2 \mu \mathrm{g} / \mathrm{dL}$ e $9,0 \mu \mathrm{g} / \mathrm{dL}$, respectivamente). Ao mesmo tempo, os autores mostraram que a distribuição geográfica dos municípios deficientes coincidiu com as regiões de carência geológica em iodo, sugerindo que o sal, mesmo que iodado adequadamente na origem, não garante a ingestão apropriada às populações nestas áreas.

Estudo realizado, posteriormente, em 2002, por Pontes e cols. (6), detectou hipotireoidismo em $12,3 \%$ da população rural e $15,9 \%$ da população urbana no município de Cabaceiras, PB. Para identificar os fatores que estariam influenciando nesta alta frequência de hipotireoidismo, realizou-se estudo transversal em 180 escolares, sorteados entre os 300 escolares com idade entre 9 e 14 anos de idade, matriculados nas escolas do município (todas públicas). Os escolares foram orientados a entregar amostra do sal utilizado em sua residência, acondicionada em um saco plástico fornecido pela equipe e o nome da marca registrada do produto. A análise quantitativa do iodo (NBR603-11/1990) no sal foi realizada no Laboratório de Química do Centro Federal de Educação Tecnológica do Rio Grande do Norte (CEFETRN).

Observou-se que o sal utilizado por $175(97,2 \%)$ dos escolares, em suas residências, era industrializado e de diversas marcas. Oitenta e cinco $(47,2 \%)$ dos escolares não souberam informar a marca de sal utilizado em suas residências, acredita-se que alguns por desconhecimento e outros por utilizarem outros tipos de sal, inclusive o de uso veterinário. Os demais por ordem decrescente de consumo foram (Tabela 1$)$ : marca $1^{\circledR}(n=32)$; marca $2^{\circledR}$ $(\mathrm{n}=22)$, marca $3^{\circledR}(\mathrm{n}=17)$, marca $4^{\circledR}(\mathrm{n}=9)$, marca $5^{\circledR}(\mathrm{n}=9)$ e $\operatorname{Marca}^{\circledast}(\mathrm{n}=6)$, sendo este último só referido pelos escolares da área rural e o da marca 3 , sal grosso. Dessas, apenas uma $(16,6 \%)$ apresentou concentração de iodo menor que a mínima recomendada pela
1 Hospital Universitário Alcides Carneiro, Universidade Federal de Campina Grande Campina Grande, PB, Brasil

${ }^{2}$ Centro Federal de Educação Tecnológica do Rio Grande do Norte (CEFETRN) Natal, RN, Brasil ${ }^{3}$ Departamento de Pediatria da Faculdade de Medicina da Bahia, Universidade Federal da Bahia (UFBA), Salvador, BA, Brasil.

Correspondência para: Alana Abrantes Nogueira de Pontes Rua José Augusto Ribeiro, 115, apto. 401, Bela Vista 584428-720 Campina Grande PB E-mail: alana@terra.com.br

Recebido em 18/Jun/2008 Aceito em 24/Nov/2008 
Anvisa $(11,11 \mathrm{mg} / \mathrm{kg})$, porém foi a que mostrou maior variedade (30\%) e é a segunda mais consumida pelos escolares (18\%). Nenhuma amostra do sal apresentou nível de iodo maior que $60 \mathrm{mg} / \mathrm{kg}$.

Apesar disso, o quantitativo de iodo, principalmente o seu excesso e suas consequências têm sido motivo de muito debate, tendo alguns estudos, inclusive o de Duarte e cols. (7), o qual confirma que escolares do estado de São Paulo têm excessiva ingestão de iodo, muito provavelmente por níveis relativamente elevados de iodo no sal destinado a consumo humano, defendendo a diminuição dos teores.

Tabela 1. Resultados do nível de iodação do sal consumido pelos escolares estudados em Cabaceiras, PB.

\begin{tabular}{|c|c|c|}
\hline Amostra do sal® & n 95/180 & Iodação $(\mathrm{mg} / \mathrm{kg})^{\star \star *}$ \\
\hline Marca 1 @ & 32 & 31,74 \\
\hline Marca $2 \AA$ & 22 & 29,62 \\
\hline Marca $3 \AA^{*}$ & 17 & 11,11 \\
\hline Marca $4 ®$ & 9 & 38,62 \\
\hline Marca 5® & 9 & 38,09 \\
\hline Marca 6® & 6 & 40,73 \\
\hline
\end{tabular}

* sal grosso; ** valor ideal 20 a 60 mg/kg.

Em conclusão, os dados do presente estudo não sugerem consumo de sal com excesso de iodo nessa região, o que é compatível com o estudo, em 1994, de Esteves e cols. (5), que mostrava deficiência em grau moderado em algumas regiões, e se contrapõe ao estudo de Duarte e cols. (7), em São Paulo. É necessário que o Ministério da Saúde e a Anvisa retomem suas avaliações periódicas sobre o estado nutricional de iodo e coloquem em prática a legislação vigente sobre iodação do sal no Brasil, inclusive obedecendo às determinações da OMS (1).

Declaração: Os autores declaram não haver conflitos de interesse científico nesta carta.

\section{REFERÊNCIAS}

1. WHO - World Health Organization. 5. ed. Report on World Nutrition. WHO; March, 2004.

2. McDowell LR. Minerals in animal and human nutrition. San Diego: Academic Presss, 1992.

3. Knobel M, Medeiros-Neto G. Moléstias associadas à carência crônica de iodo. Arq Bras Endocrinol Metab. 2004;48:53-61.

4. Esteves RZ. Determinação da iodúria em escolares brasileiros. [Acessado em 22 fev 2008] Disponível em: http://bases.bireme.br/cgibin/ wxislind.exe/iab/bcSP/? IsisScript=iah. xis\&nextAction=Ink\&base=TE SESSP\&lang=p\&format=detailed.pft\&indexSearch=ID\&exprSearch $=204804$.

5. Esteves RZ, Kasamatsu TS, Kuni IS, Furuzawa GK, Vieira JGH, Maciel RMB. Desenvolvimento de um método para a determinação da iodúria e sua aplicação da excreção urinária de iodo em escolares brasileiros. Arq Bras Endocrinol Metab. 2007;51:1477-84.

6. Pontes AAN, Costa ADM, Benício AL, Silva CRA, Morais RM, Pedrosa $C$, et al. Prevalência de doenças da tireóide em uma comunidade do nordeste brasileiro. Arq Bras Endocrinol Metab. 2002;46:544-9.

7. Duarte GC, Tomimori EK, Boriolli RA, Ferreira JE, Catarino RM, Camargo RYA, et al. Avaliação ultra-sonográfica da tireóide e determinação da iodúria em escolares de diferentes regiões do Estado de São Paulo. Arq Bras Endocrinol Metab. 2004;48:842-8. 